nguyên nhân dân đế sự khác biệt của nghiên cứu của chúng tôi so với nghiên cứu của những tác giả khác. Trình độ học vấn của mẹ thể hiện qua cách nuôi dưỡng và chăm sóc trẻ. Bà me có học vấn cao sẽ dễ dàng trong việc tiếp thu các thông tin về cách nuôi dưỡng con cũng như cách xử trí đúng khi con bị bệnh. Tuy nhiên, nhiều trường hợp người chăm sóc trực tiếp cho trẻ không phải bà mẹ, điều này sẽ ảnh hưởng đến thực hành nuôi dưỡng trẻ.

Nhiều nghiên cứu đã cho thây liên quan giữa thực hành nuôi con bằng sữa me như thời gian bú mẹ hoàn toàn, thời gian cai sữa với tình trạng dinh dưỡng ở trè. Tuy nhiên, trong nghiên cứu của chúng tôi cõ̃ mẫu có thể chưa đủ lớn, ngoài ra các đối tượng trong nghiên cứu của đều có các vấn đề về dinh dưỡng kèm theo như bệnh lý, hoặc các sai lầm nuôi dưỡng khác... Vì vậy, cần có những nghiên cứu lớn và sâu hơn để đánh giá ảnh hưởng của từng yếu tố đến tính trạng dinh dưỡng của trẻ.

\section{KẾT LUẬN}

Tỷ lệ trẻ SDD ở cả ba thể còn cao, ngoài ra có 1 tỳ lệ không nhỏ trẻ thừa cân béo phì. Một số yếu tố có liên quan đến tình trạng dinh dưỡng của trẻ, trong đó tỷ lệ SDD thể nhẹe cân cao hơn ở nhóm trẻ cân nặng lúc sinh thấp so với nhóm trẻ có cân nặng khi sinh bình thường.

TÀI LIỆ THAM KHẢO

1. Viện Dinh Dưỡng (2006), "Tình trạng dinh dưỡng trẻ em và bà mẹ năm 2005", Nhà xuất bản Y Học.

2. Chư Thị Phương Mai, Nguyễn Thị Viêt Hà (2014). Đánh giá tình trạng suy dinh dướng và một sô yếu tố ảnh hưởng đển dinh dưỡng của trẻ từ 6-24 tháng tuổi tại Phòng khám Dinh dưỡng, Bệnh viện Nhi Trung ương. Tạp chí Nhi khoa.

3. Phạm Văn Hoan, Nguyến Lan Phương và cộng sự (2009). Thức trang suy dinh dưỡng trẻ em dưới 5 tuổi, kiến thức thựcc hành nuôi con của bà me ở Xã Phù Linh, Sóc Sớn, Hà Nội 2008. Tạp chí DD̉\&TP, 5 (2).

4. Organization WH. UNICEF/WHO/The World Bank Group joint child malnutrition estimates: levels and trends in child malnutrition: key findings of the 2020 edition. 2020.

5. Brabin BJ, Premji Z, Verhoeff F. An analysis of anemia and child mortality. The Journal of nutrition. 2001;131(2):636S-648S.

6. Kátia B.R.S, Jullyana F.R.A, and all (2010). Association between malnutrition in children living in favelas, maternal nutritional status, and environmental factors. Journal de Pediatria, 86(3), 215-220.

7. WHO, UNICEF, USAID, AED, UCDAVIS and IFPRI (2008), Indicators for assessing infant and young child feeding practices, Consensus meeting, Washington, DC, pp. 5-11.

\title{
KHẢO SÁT MỐI LIÊN QUAN GIỮA GENOTYPE VÀ TÌNH TRẠNG KHÁNG CLARITHROMYCIN CỦA HELICOBACTER PYLORI Ở BỆHH NHÂN VIÊM LOÉT DẠ DÀY TÁ TRÀNG
}

Đào Thanh ${ }^{1}$, Trần Đỗ Hùng ${ }^{2}$, Trần Thị Như L $\hat{e}^{2}$, Nguyễn Văn Lâm², Tạ Văn Trầm ${ }^{4}$, Nguyễn Ngọc Hằng ${ }^{4}$, Liêu Trường Khánh ${ }^{5}$, Lê Thị Gái ${ }^{2}$, Bùi Ngọc Niệm², Âu Xuân Sâm², Huỳnh Minh Trúc ${ }^{3}$

\section{TÓM TẮT}

Đắt vấn đê: Tình trang kháng clarithromycin đang gia tăng trên toàn thế giới và là nguyên nhân phổ biến nhất dân đến thất bai trong điều trị Helicobacter pylori. Mục tiêu nghiền cứu: xác định tỷ lệ kháng clarithromycin của Helicobacter pylori ở bệnh nhân

\footnotetext{
${ }^{1}$ Trung tâm Y tế huyện Thới Lai

${ }^{2}$ Trường Đại học Y Dược Cần Thơ

${ }^{3}$ Trung tâm Kiểm soát bệnh tật Cần Thơ

${ }^{4}$ Bệnh viện Đa Khoa Trung Tầm Tiền Giang

5Bệnh viện Đa Khoa Trung Ương Cần Thơ

Chịu trách nhiệm chính: Đào Thanh

Email: daothanhtl1980@gmail.com

Ngày nhận bài: 3.8.2021

Ngày phản biện khoa học: 29.9.2021

Ngày duyệt bài: 5.10 .2021
}

viêm, loét dày - tá tràng và mối liên quan giữa genotype và tình trang kháng clarithromycin của Helicobacter pylori. Đối tượng và phương pháp nghiên cứu: Nghiên cứu cắt ngang được thực hiện trên các bệnh nhân viêm loét dạ dày tá tràng tại tỉnh Tiền Giang 5/2020 đến tháng 5/2021. Những bệnh nhân được phỏng vấn, khám lâm sàng, thu thập mẫu niêm mạc dạ dày tá tràng. Bệnh nhân được xác định nhiễm Helicobacter pylori khi có ít nhất 2 xét nghiệm nhuộm gram, urease test dương hoặc xét nghiệm nuôi cấy định danh dương tính với Helicobacter pylori. Helicobacter pylori được xác định kháng clarithromycin bằng kỹ thuật E-test và xác định genotype bằng kỹ thuật Realtime-PCR. Kết quả: Tỷ lệ đề kháng clarithromycin của vi khuẩn Helicobacter pylori trên bệnh nhân tham gia nghiên cứu là 77,3\%. Nhóm bệnh nhân nhiếm chủng Helicobacter pylori mang genotype $\operatorname{cag} \mathrm{A}(+)$ có tỷ lệ đề kháng kháng sinh cao hơn nhóm bệnh nhân nhiễm chủng Helicobacter pylori mang 
genotype cagA(-), với OR (KTC95\%): 11,25 (1,11$114,37), p=0,024$. Kết luận: bệnh nhân dương tính với Helicobacter pylori chủng $\operatorname{cagA}(+)$ nên được quan tâm đặc biệt do có khả năng đề kháng kháng sinh clarithromycin tăng cao.

Tư khóa: Helicobacter pylori, kháng kháng sinh, cagA, vacA

\section{SUMMARY}

EVALUATION OF RELATION BETWEEN HELICOBACTER PYLORI GENOTYPES AND CLARITHROMYCIN RESISTANCE IN PATIENTS HAD GASTRODUODENAL ULCER AND GASTRITIS

Background: Clarithromycin resistance is increasing worldwide and is the most common cause of Helicobacter pylori treatment failure. Objectives: This study aims to determine the rate of clarithromycin resistance of Helicobacter pylori in patients with inflammation, gastric ulcer - duodenal ulcer and the relationship between genotype and clarithromycin resistance of Helicobacter pylori. Materials and methods: This cross-sectional study was conducted on peptic ulcer patients in Tien Giang province from May 2020 to May 2021. Participants were interviewed, clinically examined, and collected samples of gastrointestinal mucosa. Patients were identified as Helicobacter pylori infection by gram stain, possitive urease test or positive culture microbiology test in Helicobacter pylori. Clarithromycin resistance in Helicobacter pylori was determined by Etest method and determined genotype by RealtimePCR technique. Results: The rate of clarithromycin resistance of Helicobacter pylori in patients participating in the study was $77.3 \%$. The group of patients infected with the Helicobacter pylori strain carrying the $\operatorname{cagA}(+)$ genotype had a higher rate of antibiotic resistance than the group of patients infected with the Helicobacter pylori strain carrying the cagA(-) genotype, with an OR (95\%CI): 11.25 (1.11114.37), $p=0.024$. Conclusions: Helicobacter pylori $\operatorname{cag} \mathrm{A}(+)$-positive patients should receive special attention because of their increased resistance to clarithromycin.

Key words: Helicobacter pylori, antibiotic resistance, CagA, VacA

\section{I. ĐẶT VẤN ĐỀ}

Helicobacter pylori là nguyên nhân của bệnh viêm loét dạ dày tá tràng và ung thư dạ dày. Điều trị tiệt trừ Helicobacter pylori phổ biến nhất hiện nay có 5 loại kháng sinh được sử dụng gồm amoxicillin, tetracycline, metronidazole, clarithromycin, levofloxacin. Phác đồ điều trị Helicobacter pylori thường kết hợp ít nhất 2 loại kháng sinh, trong đó kháng sinh clarithromycin đóng vai trò quan trọng trong phác đồ 3 thuốc gồm thuốc ức chế bơm proton (PPI-Proton-pump inhibitor). Hiệu quả của phác đồ này ngày càng giảm do tình hình đề kháng kháng sinh của Helicobacter pylori ngày càng gia tăng trên toàn thế giới, đặc biệt là clarithromycin là một kháng sinh chủ lực trong điều trị tiệt trừ Helicobacter pylori [9]. Hiệu quả tiệt trừ Helicobacter pylori giảm từ $90 \%$ xuống $60 \%-70 \%$ và có liên quan chặt chẽ đến sự đề kháng kháng sinh clarithromycin của Helicobacter pylori [3].

Chẩn đoán sớm đề kháng kháng sinh giúp giảm nguy cơ thất bại trong điều trị, hơn nữa việc xác định tỷ lệ đề kháng clarithromycin có ý nghĩa quan trọng trong việc chọn lựa phác đồ phù hợp trong điều trị Helicobacter pylori với quần thể bệnh nhân trong từng khu vực. Ngoài ra xác định genotype Helicobacter pylori có ý nghĩa dự báo các biến chứng kháng thuốc, ung thư dạ dày tá tràng nhằm giúp cho bác sĩ tích cực hơn trong công tác điêu trị. Các gen độc lực của Helicobacter pylori nằm trong một đoạn DNA có kích thước 35 - 40 kbp được gọi là đảo gây bệnh. Gen liên kết với độc tố tế bào $A$ (CagA Cytotoxin-associated gene $A$ ) và độc tố tạo không bào (VacA - vacuolating cytoxin) là những gen được nghiên cứu nhiều nhất trong số những gen khác. Gen CagA được phân lập hơn $50 \%$ chủng Helicobacter pylori, vai trò làm tăng khả năng loét dạ dày và phát triển ung thư dạ dày. Gen VacA mã hóa cytotoxin A không bào, làm tăng nguy cơ loét đường tiêu hóa và ung thư dạ dày.

Mặc dù thực tế là gen VacA đã được phẩn lập từ tất cả các chủng Helicobacter pylori, nhưng sự biến đổi alen được tìm thấy do sự đa hình ở hai vùng VacA đáng kể. Vùng đầu tiên là vùng được gọi là vùng tín hiệu $s$ (signal) và vùng thứ hai nằm ở giữa gen được gọi là vùng giữa $\mathrm{m}$ (middle). Hai alen của vùng $m, m 1$ và $m 2$, và hai alen của peptit tín hiệu s1 và s2 đã được xác định. Các dòng vi khuẩn sở hữu s1m1 có độc tính tế bào cao hơn, làm tăng khả năng viêm, teo dạ dày và ung thư biểu mô dạ dày so với các dòng vi khuẩn có kết hợp s2m2 hoặc s2 m1 [5]. Vì vậy, chúng tôi tiến hành đề tài với 2 mục tiêu:

1. Xác định tý lề kháng clarithromycin của Helicobacter pylori ở bệnh nhân viêm, loét dày tá tràng đên khám và điều trị tại bệnh viện đa khoa Trung tâm Tiền Giang

2. Mô tả sự liên quan giữa genotype của các chủng Helicobacter pylori và tình trạng đề kháng clarithromycin của Helicobacter pylori gây bệnh viêm, loét dày - tá tràng.

\section{II. ĐỐI TƯợNG VÀ PHƯƠNG PHÁP NGHIÊN CỨU 2.1. Đổi tượng nghiên cứu}

Tiêu chuẩn chọn mấu: bệnh nhân được nội soi dạ dày - tá tràng và lấy mẫu sinh thiết chẩn đoán bị viêm, loét và nhiếm Helicobacter pylori bằng xét nghiệm urease tại phòng nội soi Bệnh 
viện Đa khoa Trung tâm Tiền Giang từ tháng 5 năm 2020 đến tháng 5 năm 2021, đồng ý tham gia nghiên cứu.

Tiêu chuẩn loại trừ: bệnh nhân có tiền sử mổ da dày, đang dùng thuốc ức chế bơm proton, đang dùng thuốc chống đông, dùng kháng sinh 1 tháng trước khi nội soi, đang có thai và cho con bú.

\subsection{Phương pháp nghiên cứu}

\subsubsection{Thiết kế nghiên cứu}

Nghiên cứu cắt ngang mô tả có phân tích.

2.2. Cỡ mẫu và phương pháp chọn mẫu

Chọn mẫu theo công thức:

$$
n=z_{1-\frac{\alpha}{2}}^{2} \frac{P(1-P)}{d^{2}}
$$

Trong đó: n: cõ̃ mẫu

z: hệ số tin cậy, với $a=0,05 \rightarrow z=1,96$

$\mathrm{d}$ (sai số cho phép) $=0,08$

P: kết quả nghiên cứu của Dương Thị Thanh năm 2018 cho thấy tỷ lệ đề kháng kháng sinh clarithromycin là $96,2 \%[4] \rightarrow P=0,962$. Vậy $n$ tính được và làm tròn là 22 mẫu.

Chọn mẫu thuận tiện. Tất cả các bệnh nhân được nội soi chẩn đoán bị viêm, loét dạ dày - tá tràng xác định có nhiếm Helicobacter pylori bằng thử nghiệm urease dương tính thoả tiêu chuẩn chọn tại Bệnh viện Đa khoa Trung tâm Tiền Giang từ 01/5/2020 cho đến khi đủ mẫu.

2.2.3. Nội dung nghiên cứu. Thu thập dũ liệu dựa trên phiếu thu thập số liệu xây dựng sẵn vể đặc điểm dân số - xã hội học như: giới tính, tuổi, trình độ học vấn, nghề nghiệp, nới sống; các đặc điểm về tiền sử sử dụng rượu bia, hút thuốc lá; đặc điểm lâm sàng: triệu chứng của viêm - loét dạ dày; đặc điểm cận lẩm sàng: vị trí tổn thương trên nội soi.

Xác định tỷ lệ đề kháng clarithromycin của Helicobacter pylori dựa vào nồng độ ứng chế tối thiểu (Minimum inhibitory concentration - MIC) của kết quả kháng sinh đồ bằng kỹ thuật $\mathrm{E}$-test: xác định vi khuẩn Helicobacter pylori nhạy với kháng sinh clarithromycin khi MIC $\leq 0,5 \mu \mathrm{g} / \mathrm{mL}$, kháng với kháng sinh clarithromycin khi MIC > $0,5 \mu \mathrm{g} / \mathrm{mL}$. Xác định các kiểu gen CagA, VacA bằng PCR và giải trình tự. Tách chiết DNA: từ mảnh sinh thiết.

Các kỹ thuật trong nghiên cứu:

Thử nghiệm urease test: dùng kim vô trùng lấy mẫu mô dạ dày được sinh thiết đầu tiên ở hang vị, để vừi mấu mồ này ngập trong giếng gel Pylori-test. Kết quả được đọc trong vòng 1 giờ. Nếu dung dịch đổi màu hồng cánh sen là dương tính Helicobacter.

Kỹ thuật nhuộm Gram: nhỏ dung dịch gentian lên tiêu bản, sau 1 - 2 phút rửa tiêu bản bằng nước. Nhỏ dung dịch cố định màu lugol để 30 giây sau đó rửa nước. Nhỏ cồn $95^{\circ}$ lên tiêu bản để tẩy màu. Khi thấy màu tím trên lam kính vừa phải hết thì rửa nước ngay. Nhỏ dung dịch safranin để 1 - 2 phút, rửa nước kỹ, để khô, soi kính hiển vi (vật kính $100 \mathrm{X}$, có dùng dầu soi kính). Kết quả phát hiện vi khuẩn Gram âm hình cánh chim hải âu, cong, mảnh, dấu ngã, chữ $\mathrm{S}$.

Nuôi cấy định danh bằng phương pháp thông thường: mẫu bệnh phẩm sau khi nhận được cấy ngay vào môi trường chọn lọc Mueller Hinton Horse Blood Agar. Ủ ở $37^{\circ} \mathrm{C}$ với 3\%-5\% $\mathrm{O}_{2}, 5 \%-10 \% \mathrm{CO}_{2}$ và độ ẩm thích hợp. Đọc kết quả sau khi ủ 3-5 ngày. Mẫu bệnh phẩm được xác định là có sự hiện diện của vi khuẩn Helicobacter pylori khi có các thử nghiệm định danh sau đây: urease dương tính, catalase dương tính, oxidase dương tính.

Kỹ thuật Realtime-PCR: chuẩn bị dụng cụ; mẫu; hóa chất, tách chiết DNA bằng hệ thống tự động, chạy Realtime-PCR, đọc kết quả.

Các bệnh nhân khi vào viện được lập hồ sơ bệnh án tại Phòng Khám bệnh theo mẫu bệnh án chính thức của Bệnh viện, đồng thời được trích xuất vào phiếu thu thập số liệu. Các bệnh án chính thức và phiếu thu thập số liệu được theo dõi cho đến khi bệnh nhân ra viện. Việc theo dõi bệnh nhân và trích xuất thông tin từ bệnh án chính thức vào phiếu thu thập số liệu được thực hiện bởi đội ngũ bác sĩ của Phòng khám bệnh và các khoa điều trị Bệnh viện Đa khoa Trung tâm Tiềng Giang, sau khi được tập huấn và hướng dẫn đây đủ, cẩn thận về các yêu cầu của mục tiêu nghiên cứu chỉ tiêu đánh giá.

Dữ liệu được nhập và xử lý bằng phần mềm SPSS 18.0. Các biến số được trình bày dưới dạng bảng tần số, tỷ lệ phần trằm (\%) hoặc biểu đồ. Sử dụng test thống kê Chi bình phương (Chisquare - $x 2$ ) để xác định sự khác biệt về 2 tỷ lệ. Xác định sự khác biệt có ý nghĩa thống kê với mức ý nghĩa $\mathrm{p}<0,05$.

\section{KẾT QUẢ NGHIÊN CỨU}

3.1. Đặc điểm của mẫu nghiên cứu

3.1.1. Đặc điểm dân số- xã hội

Bảng 1. Đặc điểm chung của đôi tượng nghiên cứu

\begin{tabular}{|c|c|c|c|}
\hline \multicolumn{2}{|c|}{ Đặc điểm } & Tân số & Tỷ lệ (\%) \\
\hline \multirow{2}{*}{$\begin{array}{c}\text { Nhóm } \\
\text { tuổi }\end{array}$} & $\leq 30$ & 8 & 36,4 \\
\cline { 2 - 4 } & $31-59$ & 12 & 54,5 \\
\cline { 2 - 4 } & $\geq 60$ & 2 & 9,1 \\
\hline \multirow{2}{*}{ Giới tính } & Nam & 8 & 36,4 \\
\cline { 2 - 4 } & Nữ & 14 & 63,6 \\
\hline Trình độ & Tiếu học & 5 & 22,7 \\
\hline
\end{tabular}


VIETNAM MEDICAL JOURNAL N²2 - OCTOBER - 2021

\begin{tabular}{|c|c|c|c|}
\hline \multirow[t]{3}{*}{ học vấn } & Trung học cơ sở & 5 & 22,7 \\
\hline & $\begin{array}{c}\text { Trung học phố } \\
\text { thông }\end{array}$ & 7 & 31,8 \\
\hline & Đại học & 5 & 22,7 \\
\hline \multirow{5}{*}{$\begin{array}{l}\text { Nghề } \\
\text { nghiệp }\end{array}$} & $\begin{array}{c}\text { Cán bồ - Văn } \\
\text { phòng }\end{array}$ & 5 & 22,7 \\
\hline & Công nhân & 4 & 18,2 \\
\hline & Nông dân & 5 & 22,7 \\
\hline & $\begin{array}{c}\text { Học sinh - Sinh } \\
\text { viên }\end{array}$ & 2 & 9,1 \\
\hline & Khác & 6 & 27,3 \\
\hline \multirow{2}{*}{$\begin{array}{l}\text { Tiền sử } \\
\text { hút thuốc }\end{array}$} & Có & 5 & 22,7 \\
\hline & Không & 17 & 77,3 \\
\hline \multirow{2}{*}{$\begin{array}{l}\text { Tiên sử } \\
\text { uống } \\
\text { rượu }\end{array}$} & Có & 8 & 36,4 \\
\hline & Không & 14 & 63,6 \\
\hline
\end{tabular}

Nhận xét: Triệu chứng phổ biến nhất là đau bụng vùng thượng vị $(77,3 \%)$ và đầy hơi khó tiểu $(68,2 \%)$.

Bảng 3. Phân bố vị trí tổn thương trên nội soi của bệnh nhân tham gia nghiên cứu $(n=22)$

\begin{tabular}{|c|c|c|}
\hline Vị trí tổn thương & Tân số & Tỷ lệ (\%) \\
\hline Hang vị & 17 & 77,3 \\
\hline Thân vị & 3 & 13,6 \\
\hline Khác & 2 & 9,1 \\
\hline
\end{tabular}

Nhân xét: Vị trí tổn thương phổ biến nhất là tại hang vị $(77,3 \%)$.

3.2. Tình trạng đề kháng kháng sinh của vi khuẩn Helicobacter pyori

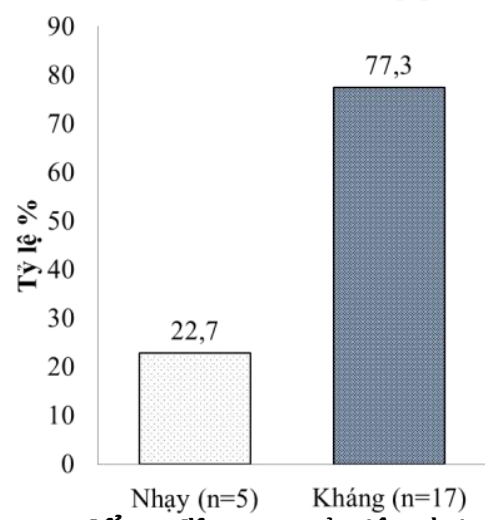

Nhân xét: Nhom tuối $31-59$ chiêm da số vấn Trung học phổ thông chiếm đa số $(31,8 \%)$. Cán bộ - Văn phòng và Nông dân chiếm tỷ lệ cao nhất $(22,7 \%) .22,7 \%$ có hút thuốc lá. $36,4 \%$ có uống rươu bia.

3.1.2. Đặc điểm lâm sàng, cận lâm sàng

Bảng 2. Đặc điểm lâm sàng của bệnh nhân tham gia nghiển cứu $(n=22)$

\begin{tabular}{|c|c|c|}
\hline Triệu chứng & Tân số & Tỷ lệ (\%) \\
\hline $\begin{array}{c}\text { Đau bưng vừng } \\
\text { thượng vị }\end{array}$ & 17 & 77,3 \\
\hline Nóng rát thượng vị & 12 & 54,5 \\
\hline Đây hơi - khó tiêu & 15 & 68,2 \\
\hline Buồn nôn & 12 & 54,5 \\
\hline Nôn & 7 & 31,8 \\
\hline
\end{tabular}

Biểu đồ 1. Tỷ lệ tình trạng đề kháng clarithromycin của vi khuẩn Helicobacter pyori trên bênh nhân tham gia nghiên cứu $(n=22)$

Nhân xét: Tỷ lệ đề kháng clarithromycin của vi khuẩn Helicobacter pyori trên bệnh nhân tham gia nghiên cứu là 77,3\%.

3.3. Mối liên quan giữa genotype của Helicobacter pylori và tình hình kháng clarithromycin

Bảng 4. Phân bố genotype của vi khuẩn Helicobacter pyori trong mẫu nghiên cứu

\begin{tabular}{|c|c|c|c|c|c|c|}
\hline \multirow{2}{*}{ Genotype } & \multicolumn{2}{|c|}{ CagA(+) } & \multicolumn{2}{c|}{ CagA(-) } & \multicolumn{2}{c|}{ Tống } \\
\cline { 2 - 7 } & $\mathbf{n}$ & $\mathbf{\%}$ & $\mathbf{n}$ & $\mathbf{\%}$ & $\mathbf{n}$ & $\mathbf{\%}$ \\
\hline VacA s $1 / \mathrm{m}$ & 2 & 9,1 & 1 & 4,5 & $\mathbf{3}$ & $\mathbf{1 3 , 6}$ \\
\hline VacA s1/m1 & 9 & 40,9 & 1 & 4,5 & $\mathbf{1 0}$ & $\mathbf{4 5 , 5}$ \\
\hline VacA s1/m2 & 6 & 27,3 & 3 & 13,6 & $\mathbf{9}$ & $\mathbf{4 0 , 9}$ \\
\hline Tống & $\mathbf{1 7}$ & $\mathbf{7 7 , 3}$ & $\mathbf{5}$ & $\mathbf{2 2 , 7}$ & $\mathbf{2 2}$ & $\mathbf{1 0 0 , 0}$ \\
\hline
\end{tabular}

Nhân xét: $77,3 \%$ bênh nhân có genotype CagA(+), 22,7\% bệnh nhân có genotype CagA(-). $45,5 \%$ và $40,9 \%$ bệnh nhân có genotype VacA s1/m1 và vacA s1/m2. Chỉ có $13,6 \%$ bệnh nhân có genotype là vacA $\mathrm{s} 1 / \mathrm{m}(-)$

Bảng 5. Liên quan giứa genotype CagA với tinh hình kháng clarithromycin $(n=22)$

\begin{tabular}{|c|c|c|c|c|c|}
\hline \multirow[b]{2}{*}{ Genotype } & \multicolumn{2}{|c|}{ Helicobacter pylori đề kháng clarithromycin } & \multirow[b]{2}{*}{ OR } & \multirow[b]{2}{*}{ KTC95\% } & \multirow[b]{2}{*}{ p } \\
\hline & Có (\%) & Không (\%) & & & \\
\hline $\operatorname{CagA}(+)$ & $15(88,2)$ & $2(11,8)$ & \multirow{2}{*}{11,25} & \multirow{2}{*}{$1,11-114,37$} & \multirow{3}{*}{$0,024 *$} \\
\hline CagA(-) & $2(40,0)$ & $3(60,0)$ & & & \\
\hline Tống & $17(77,3)$ & $5(22,7)$ & & & \\
\hline
\end{tabular}

*Fisher's Exact Test

Nhận xét: nhóm bênh nhân nhiễm chủng Helicobacter pylori mang genotype CagA(+) có tỷ lẹ đề kháng kháng sinh cao hơnn nhóm bệnh nhân nhiễm chủng Helicobacter pylori mang genotype CagA(), với OR (KTC95\%): 11,25 (1,11-114,37), p=0,024. 
Bảng 6. Liên quan giữa genotype VagA với tình hình kháng clarithromycin ( $n=22)$

\begin{tabular}{|c|c|c|c|c|c|}
\hline \multirow{2}{*}{ Genotype } & Helicobacter pylori đề kháng clarithromycin & OR & \multirow{2}{*}{ KTC95\% } & \multirow{2}{*}{ p } \\
\cline { 2 - 3 } & Có (\%) & Không (\%) & & & \\
\hline VacA s1/m & $2(66,7)$ & $1(33,3)$ & Ref. & - & - \\
\hline VacA s1/m1 & $7(70,0)$ & $3(30,0)$ & 0,86 & $0,06-13,48$ & $1,000^{*}$ \\
\hline VacA s1/m2 & $8(88,9)$ & $1(11,1)$ & 0,25 & $0,10-5,99$ & $0,455^{*}$ \\
\hline Tống & $\mathbf{1 7}(\mathbf{7 7 , 3})$ & $\mathbf{5 ( 2 2 , 7 )}$ & & & \\
\hline
\end{tabular}

*Fisher's Exact Test

Nhận xét: Không có sự khác biệt có ý nghĩa thông kê về tỷ lệ đề kháng clarithromycin giữa các nhóm bệnh nhân nhiễm các chủng Helicobacter pylori mang genotype VagA về tỷ lệ đề kháng clarithromycin $(p>0,05)$.

Bảng 7. Liên quan giữa kêt hợp genotype VagA và CagA với tình hình kháng clarithromycin ( $n=22)$

\begin{tabular}{|c|c|c|c|c|}
\hline \multirow{2}{*}{ Genotype } & Helicobacter pylori đề kháng clarithromycin & \multirow{2}{*}{ Tổng } & \multirow{2}{*}{$\mathbf{p}$} \\
\cline { 2 - 3 } & Có (\%) & Không (\%) & & \\
\hline CagA(-)+VacA S1m & $0(0,0)$ & $1(100,0)$ & $1(4,5)$ & \\
\hline CagA $(+)+$ VacA S1m & $2(100,0)$ & $0(0,0)$ & $2(9,1)$ & \multirow{2}{*}{0,096} \\
\hline CagA $(-)+$ VacA S1m1 & $0(0,0)$ & $1(100,0)$ & $1(4,5)$ & \\
\hline CagA $(+)+$ VacA S1m1 & $7(77,8)$ & $2(22,2)$ & $9(40,9)$ & \\
\hline CagA $(-)+$ VacA S1m2 & $2(66,7)$ & $1(33,3)$ & $3(13,6)$ & \\
\hline CagA $(+)+$ VacA S1m2 & $6(100,0)$ & $0(0,0)$ & $6(27,3)$ & \\
\hline Tống & $\mathbf{1 7}(\mathbf{7 7 , 3})$ & $\mathbf{5 ( 2 2 , 7 )}$ & $\mathbf{2 2 ( 1 0 0 , 0 )}$ & \\
\hline
\end{tabular}

Nhận xét: Không có sự khác biệt có ý nghĩa thống kê về tỷ lệ đề kháng clarithromycin giữa các nhóm bệnh nhân nhiễm các chủng Helicobacter pylori mang kết hợp genotype VacA và CagA về tỷ lệ đề kháng clarithromycin ( $p>0,05)$.

\section{BÀN LUẬN}

4.1. Tình trạng đề kháng kháng sinh của vi khuẩn Helicobacter pyori. Kết quả nghiên cứu của chúng tôi cho thấy tỷ lệ đột biến đề kháng kháng sinh clarithromycin của Helicobacter pylori trong mẫu nghiên cứu là $77,3 \%$. Kết quả này cho thấy tỷ lệ đột biến đề kháng kháng sinh clarithromycin tại Tiền Giang rất cao. Điều này có thể giải thích do việc sử dụng kháng sinh nhóm macrolid hiện nay quá rộng rãi. Việc tiêu thụ nhiều kháng sinh clarithromycin, đặc biệt là trong điều trị các bệnh đường hô hấp, có lẽ là nguyên nhân chính làm tăng sức đề kháng của Helicobacter pylori với clarithromycin. Kết quả nghiên cứu của chúng tôi cảnh báo việc sử dụng quá mức kháng sinh clarithromycin trong cộng đồng tại Tiền Giang.

Kết quả nghiên cứu của chúng tôi cao hơn nghiên cứu của Đặng Ngọc Quý Huệ năm 20142016 tại bệnh viện Thống Nhất (Đồng Nai) trên 153 bệnh nhân cho thây tỷ lệ đề kháng kháng sinh clarithromycin của Helicobacter pylori là $72,6 \%$ [6]. Theo nghiên cứu của Ratha Korn Vilaichone tại các nước Đông Nam Á năm 2015 cho thấy tỷ lệ đề kháng kháng sinh clarithromycin thay đổi ở các nước Đông Nam Á, cao ở Việt $\operatorname{Nam}(30 \%)$ và Cambodia (43\%), trung bình đến cao ở Singapore (17\%) và thấp ở
Malaysia (6,8\%), Philippines (2\%) và Myanmar (0\%)[7]. Theo kết quả nghiên cứu của Trân Văn Huy giai đoạn 2012-2014 và 2015-2017 tại miền Trung cho thây tỷ lệ đề kháng kháng sinh clarithromycin là $53,8 \%$, tăng từ $40,4 \%$ năm 2012-2014 lên 70,2\% năm 2015-2017 $(p=0,045)[8]$. Còn theo nghiên cứu của Camelia Quek tại 13 bệnh viện phía Nam năm 2015-2016 cho thấy tỷ lệ đề kháng kháng sinh clarithromycin lên đến 85,5\% [3].

4.3. Mối liên quan giữa genotype Helicobacter pylori với tình hình kháng clarithromycin. Để xác định genotype cagA và vacA trong Helicobacter pylori, tất cả các chủng vi khuẩn Helicobacter pylori trong nghiên cứu sẽ được phân lập bằng PCR. Kết quả của chúng tôi cho thấy, 77,3\% bệnh nhân có genotype CagA (+), 22,7\% bệnh nhân có genotype CagA(-). $45,5 \%$ và $40,9 \%$ bệnh nhân có genotype VacA s1m1 và VacA s1m2. Chỉ có $13,6 \%$ bệnh nhân có genotype là VacA s1m. Kết quả này của chúng tôi phù hợp với tác giả Đặng Thúy Hà năm 20182019 tại Hà Nội khi cho thấy 71,1\% bệnh nhân có genotype $\operatorname{CagA}(+)$ [1]. Kết quả của chúng tôi khác với nghiên cứu Phạm Hồng Khánh năm 2019-2020 trên 121 bệnh nhân tại bệnh viện Trung ương Quân đội 108 và Bệnh viện 103 (Học viện Quân Y), khi cho thấy genotype cagA Đông Á chiếm tỷ lệ cao $(94,4 \%)$, VacAs1 chiếm tỷ lệ 
(100\%), VacA s1m1, VacA s1m2 chiếm tỷ lệ tương 46,5\%; 50,7\% [2]. Theo nghiên cứu của Judit Alarcón-Millán trên trên 144 bênh nhân được chọn từ Khoa Tiêu hóa Bệnh viện Đa khoa Raymundo Abarca Alarcón và Đơn vị Chuyên khoa Nội soi Tiêu hóa, tại Chilpancingo, Bang Guerrero (Mexico), khi cho thấy các CagA đã được phát hiện ở $77,8 \%$ của các chủng. Các biến thể alen VacA được xác định ở $100 \%$ các chủng. Các alen s1 được tìm thấy trong $84,5 \%$ của các chủng và sự kết hợp của các alen của VacA s1m1 trong $80 \%$ (36/45); $15,5 \%$ chủng có kiểu gen VacA $s 1 m 2$ và $2,2 \%$ kiểu kết hợp $s 1 m 2$ và s1m1/s1m2 [4].

Về sự liên quan giữa genotype Helicobacter pylori với tình hình kháng clarithromycin, kết quả của chúng tôi cho thấy nhóm bệnh nhân nhiếm chủng Helicobacter pylori mang genotype $\operatorname{cagA}(+)$ có tỷ lệ đề kháng kháng sinh cao hơn nhóm bệnh nhân nhiễm chủng Helicobacter pylori mang genotype CagA(-), với OR (KTC95\%): $11,25 \quad(1,11-114,37), \quad \mathrm{p}=0,024$. Không có sự khác biệt có ý nghĩa thống kê về tỷ lệ đề kháng clarithromycin giữa các nhóm bệnh nhân nhiễm các chủng Helicobacter pylori mang genotype VagA, dạng kết hợp genotype VagA và CagA về tỷ lệ đề kháng clarithromycin $(p>0,05)$. Kết quả này khác với nghiên cứu của Judit Alarcón-Millán năm 2016 tại Mexico, khi cho thây không có sự khác biệt có ý nghĩa thống kê về tỷ lệ bệnh nhẩn nhiễm vi khuẩn Helicobacter pylori đề kháng kháng sinh clarithromycin giữa các nhóm bệnh nhân nhiễm các chủng Helicobacter pylori mang genotype CagA [4].

Theo nghiên cứu của María R. Baroni năm 2018 tại Bệnh viện José María Cullen (Argentina), khi cho thấy vacA m1s1 là kiểu gen thường gặp nhất trong số các chủng kháng thuốc [5]. Do thực tế là trong số các kiểu gen VacA, thì kiểu gen VacA s1m1 là đôc lực nhất và các báo cáo trước đây đã mô tả tỷ lệ diệt trừ cao hơn khi có nhiều chủng độc lực hơn. Về bản chất, một số chủng Helicobacter pylori có thể nhạy cảm với điều trị kháng sinh hơn những chủng khác. Báo cáo trước đây đã chỉ ra rằng các genotype $\operatorname{CagA}(-)+$ VacA s2m2 có khả năng kháng với kháng sinh hơn $\operatorname{CagA}(+)+$ VacA s1m1 và $\operatorname{Cag} \mathrm{A}(+)+\operatorname{VacA} \operatorname{s} 1 \mathrm{~m} 2$. Các chủng $\operatorname{cag} \mathrm{A}(+)+$ VacA s1 có thể sinh sôi nhanh hơn CagA(-) + VacA s2 và do đó sẽ nhạy cảm hơn với hoat tính kháng sinh can thiệp vào quá trình trao đổi chất của tế bào đang phân chia.

\section{KẾT LUÂ̂N}

Tỷ lệ đề kháng clarithromycin của vi khuẩn Helicobacter pyori trên bệnh nhân tham gia nghiên cứu là $77,3 \%$. Nhóm bệnh nhân nhiểm chủng Helicobacter pylori mang genotype $\mathrm{CagA}(+)$ có tỷ lệ đề kháng kháng sinh cao hơn nhóm bệnh nhân nhiếm chủng Helicobacter pylori mang genotype $\operatorname{CagA}(-)$, với OR (KTC95\%): $11,25 \quad(1,11-114,37), \quad p=0,024$. Không có sự khác biệt có ý nghĩa thống kê về tỷ lệ đề kháng clarithromycin giữa các nhóm bệnh nhân nhiễm các chủng Helicobacter pylori mang genotype VagA, dạng kết hợp genotype VagA và CagA về tỷ lệ đề kháng clarithromycin $(p>0,05)$. Đối với bệnh nhân dương tính với Helicobacter pylori chủng $\mathrm{CagA}(+)$ nên được quan tâm đặc biệt do có khả năng đề kháng kháng sinh clarithromycin tăng cao.

\section{TÀI LIỆU THAM KHẢO}

1. Đăng Thúy Hà (2020), Mối liên hê giữa yễu tố độ̣c lực của Helicobacter pyori và biếu hiện lâm sàng ở bệnh nhi: Những giá trị trong chỉ định điều trị, Tạp chí Khoa học và Cốn nghệ Việt Nam, 61(11), trang 52-57.

2. Phạm Hî̀ng Khánh (2021), Tần suất và các yếu tố độc lực của Helicobacter pylori ở bệnh nhân viêm da dày mạn, Tạp chí $Y$ học Việt Nam, 505, trang 65-68.

3. Camelia Quek, Son T. Pham, Kieu T. Tran et al. (2016), Antimicrobial susceptibility and clarithromycin resistance patterns of Helicobacter pylori clinical, F1000Research, 5, page: 671.

4. Judit Alarcón-Millán (2016), Clarithromycin resistance and prevalence of Helicobacter pylori virulent genotypes in patients from Southern México with chronic gastritis, Infection, Genetics and Evolution, 44, pp: 190-198.

5. María R. Baroni (2018), Usefulness of rapid urease test samples for molecular analysis of clarithromycin resistance in Helicobacter pyloriUtilidad de las muestras de test rápido de ureasa para el análisis molecular de resistencia a claritromicina en Helicobacter pylori, Revista Argentina de Microbiología, 50(4), pp: 359-364.

6. Ngoc Quy Hue Dang, Thi Minh Thi Ha, SiTuan Nguyen et al. (2020), High rates of clarithromycin and levofloxacin resistance of Helicobacter pylori in patients with chronic gastritis in the south east area of Vietnam, Journal of Global Antimicrobial Resistance, 22, pp: 620-624.

7. Ratha Korn Vilaichone (2018), Prevalence and Pattern of Antibiotic Resistant Strains of Helicobacter Pylori Infection in ASEAN, Asian Pac J Cancer Prev, 19(5), pp: 1411-1413.

8. Van Huy Tran (2018), Characterisation of point mutations in domain $V$ of the $23 \mathrm{~S}$ rRNA gene of clinical Helicobacter pylori strains and clarithromycin-resistant phenotype in central Vietnam, Journal of Global Antimicrobial Resistance, 16, pp: 87-91. 